\title{
Pituitary magnetic resonance imaging abnormalities in young female patients with hypogonadotropic hypogonadism
}

\author{
Ji-Yeon Kang ${ }^{1, *}$, Sang Heum Kim ${ }^{2, *}$, Hounyoung Kim ${ }^{3}$, Hyojin Ki ${ }^{1}$, Mee-Hwa Lee ${ }^{1}$ \\ ${ }^{1}$ Department of Obstetrics and Gynecology, ${ }^{2}$ Department of Radiology, ${ }^{3}$ Fertility Center of CHA Bundang Medical Center, CHA Bundang Medical \\ Center, CHA University, Seongnam, Korea
}

\section{Objective}

To elucidate the association between clinical and laboratory characteristics and pituitary magnetic resonance imaging (MRI) abnormalities in young female patients with hypogonadotropic hypogonadism ( $\mathrm{HH})$.

\section{Methods}

We retrospectively investigated a series of 74 female patients (age range, 14-42 years) with normoprolactinemic $\mathrm{HH}$ who underwent pituitary MRI. Pubertal milestones and hormonal features of patients with small pituitary glands (PGs) and space-occupying lesions were compared with those of patients with normal PGs.

\section{Results}

The overall frequency of abnormal PGs was $35.1 \%$, with space-occupying lesions observed in 8 patients (10.8\%), and small PG observed in 18 patients (24.3\%). The mean serum gonadotropin level was not different between patients with and without pituitary MRI abnormalities ( $P>0.05)$. Space-occupying lesions were not associated with low gonadotropin levels, type of amenorrhea, or presence of secondary sex characteristics. The frequency of spaceoccupying lesions was higher in patients with interrupted puberty $(25.0 \%)$ than in patients who did not go through puberty $(4.8 \%)$ or had a normal puberty $(9.8 \%)$, but were not statistically significant $(P>0.05)$. Small PG was associated with low gonadotropin levels and type of amenorrhea $(P<0.05)$.

\section{Conclusion}

Clinically significant space-occupying lesions were not associated with low gonadotropin levels, type of amenorrhea, or presence of secondary sex characteristics. However, the frequency of space-occupying lesions was higher in patients with interrupted puberty than in patients who did not go through puberty or who with normal puberty.

Keywords: Hypogonadotropic hypogonadism; Amenorrhea; Delayed puberty; Magnetic resonance imaging

\section{Introduction}

Hypogonadotropic hypogonadism $(\mathrm{HH})$ refers to insufficient gonadal sex steroid production secondary to inadequate pituitary gonadotropin stimulation [1]. In female patients, $\mathrm{HH}$ is clinically characterized by amenorrhea, infertility, and/ or delayed sexual development. In addition, a low estrogen environment increases the risk of osteoporosis and bone fracture [2-4].

In general, the underlying causes of $\mathrm{HH}$ are classified as congenital, functional, or acquired structural; the frequency of each condition is different in patients with primary and secondary amenorrhea [5-7]. Functional hypothalamic amen-
Received: 2018.09.17. Revised: 2018.12.05. Accepted: 2019.01.29. Corresponding author: Mee-Hwa Lee

Department of Obstetrics and Gynecology, CHA Bundang Medical Center, CHA University, 59 Yatap-ro, Bundang-gu, Seongnam 13496, Korea

E-mail: yeegen@cha.ac.kr

https://orcid.org/0000-0001-9159-3961

${ }^{\star}$ These authors contributed equally to this work.

Articles published in Obstet Gynecol Sci are open-access, distributed under the terms of the Creative Commons Attribution Non-Commercial License (http://creativecommons. org/licenses/by-nc/3.0/) which permits unrestricted non-commercial use, distribution, and reproduction in any medium, provided the original work is properly cited.

Copyright $\odot 2019$ Korean Society of Obstetrics and Gynecology 


\title{
Obstetrics \& Gynecology Science
}

\author{
Vol. 62, No. 4, 2019
}

orrhea $(\mathrm{HA})$, the most prevalent form of female $\mathrm{HH}$, is amenorrhea with a diagnosis of exclusion [8]. When evaluating patients with $\mathrm{HH}$, physicians should exclude the possibility of uncommon but serious structural hypothalamic-pituitary (H-P) abnormalities, such as space-occupying lesions, infiltrative diseases, infections, irradiation, or head trauma [1,9-11].

The most useful imaging modality to date for the diagnosis of $\mathrm{H}-\mathrm{P}$ abnormalities is pituitary magnetic resonance imaging (MRI) [12]; however, because testing is expensive and structural pituitary abnormalities occur at a low frequency, there have been debates regarding whether pituitary MRI should be performed in the routine evaluation of patients with $\mathrm{HH}$ $[13,14]$. Nonetheless, a few studies have reported the efficiency of pituitary MRI in male patients with $\mathrm{HH}$ [13-16], although strategies for determining the necessity of pituitary MRI remain inconclusive. Furthermore, there has been a lack of information regarding the indications for pituitary imaging in female patients with $\mathrm{HH}$.

The objectives of this study were to elucidate the association of pubertal milestones as well as hormonal features with pituitary MRI abnormalities in women with $\mathrm{HH}$, and to identify predictors of abnormal pituitary lesions.

\section{Materials and methods}

\section{Study samples}

We retrospectively analyzed a series of 74 female cases that underwent pituitary MRI during evaluations for $\mathrm{HH}$. The age range of the study population was 14-42 years (mean, 23.9 years). All patients were seen in a gynecological endocrinology clinic at CHA Bundang Medical Center, Gyeonggido, Korea, presenting with primary or secondary amenorrhea between July 2000 and October 2015.

All patients were clinically diagnosed with $\mathrm{HH}$ based on the findings of primary or secondary amenorrhea, clinical and/ or biochemical hypogonadism, and low to normal folliclestimulating hormone (FSH) levels. Patients with higher basal prolactin levels ( $>29.2 \mathrm{ng} / \mathrm{mL}$, as stated by reference range) were excluded; however, one patient with a space-occupying lesion with basal prolactin level of $36.0 \mathrm{ng} / \mathrm{mL}$ was included in the study. In most cases, the indication for pituitary MRI was $\mathrm{HH}$ that persisted more than 6 months or which caused primary amenorrhea without apparent functional causes, including undernutrition, psychological stress, excessive exer- cise, or chronic illness [7]. To avoid the high cost of pituitary MRI in undisclosed functional patients with $\mathrm{HH}$, pituitary MRI was performed in patients whose symptoms did not improve after a sufficient period of observation. Accordingly, the duration of symptoms in patients with secondary amenorrhea in the present study was considerably long, with a mean duration of 39.3 months.

\section{Clinical, pubertal, and laboratory characteristics}

Medical charts were reviewed for body weight, height, body mass index (BMI), type of amenorrhea (primary vs. secondary), and the presence or absence of naturally occurring secondary sex characteristics. Basal serum levels of FSH, luteinizing hormone $(\mathrm{LH})$, prolactin, and thyroid-stimulating hormone (TSH) were assessed in all patients. The serum estradiol level was measured in 58 of 74 patients. In 10 of these patients, an excessively high low-normal limit ( $>20 \mathrm{pg} / \mathrm{mL}$ ) had been applied to discriminate very low serum concentrations, such that the results were unsuitable for this study. Therefore, only 48 of 74 patients were appropriately analyzed for serum levels of estradiol. Patients were classified into three groups according to the type of pubertal development: no puberty group (primary amenorrhea with no secondary sex characteristics), interrupted puberty group (primary amenorrhea with naturally occurring secondary sex characteristics), and normal puberty group (secondary amenorrhea with normal secondary sex characteristics).

\section{Assessment of pituitary magnetic resonance imaging diagnoses}

Patients were classified into three groups according to the pituitary MRI results: normal pituitary MRI group (no abnormal results in the H-P area), space-occupying lesion group (lesions in the $\mathrm{H}-\mathrm{P}$ area with largest diameter $>1.0 \mathrm{~cm}$ ), and small pituitary gland (PG) group (height of $P G<2$ standard deviations (SDs) of the age mean) [17]. As there was no consensus regarding the definition of a 'small' $P G$, we used $<2$ SDs of age mean for further analysis. Since we excluded patients with hyperprolactinemia, pituitary microadenomas less than $1.0 \mathrm{~cm}$ at the largest diameter were infrequently identified in this study. To investigate the characteristics of clinically significant pituitary space-occupying lesions greater than $1 \mathrm{~cm}$ in diameter, two patients with non-functioning pituitary microadenomas, with diameters of 3 and $6 \mathrm{~mm}$, respectively, as well as a patient with small Rathke's cyst with a diameter of 


\section{Obstetrics \& Gynecology Science}

$4 \mathrm{~mm}$, were included in the normal pituitary MRI group. All MRI scans were re-evaluated by an expert in neuroimaging (S.K.).

\section{Statistical analysis}

For multiple comparisons, analysis of variance was used, followed by Tukey's honest significant difference test or GamesHowell test. To compare 2 groups of numerical data, the Student's $t$-test was used. The proportions of various characteristics were compared using the $\chi^{2}$ test or Fisher's exact test. In all cases, $P$-values $<0.05$ were considered significant.

\section{Results}

\section{Demographics and hormonal characteristics}

The demographics and hormonal characteristics of the 74 patients are presented in Table 1 . The mean age $\pm S D$ at diagnosis was $23.9 \pm 6.1$ years (range, $14-42$ years); 21 patients $(28.4 \%)$ presented with primary amenorrhea with no secondary sex characteristics (no puberty), 12 (16.2\%) with primary amenorrhea and naturally-occurring secondary sex characteristics (interrupted puberty), and 41 (55.4\%) with secondary amenorrhea and normal secondary sex characteristics (normal puberty). The mean duration \pm SD of amenorrhea in 41 patients with secondary amenorrhea was
39.3 \pm 35.4 months (range, 5-156 months). The mean age at diagnosis was lower in the interrupted puberty group (20.5 years) compared to that in the normal puberty group (25.5 years) $(P=0.025)$. BMI ( $P=0.131)$, serum prolactin levels $(P=0.664)$, and serum TSH $(P=0.125)$ levels were similar in the three groups at different stages of pubertal development. As expected, the mean levels of basal serum LH $(P<0.0001)$, FSH $(P<0.0001)$, and estradiol $(P=0.003)$ were significantly lower in the no puberty group compared to those in the normal puberty group.

\section{Frequency of abnormal pituitary magnetic resonance imaging diagnoses}

The overall frequency of abnormal pituitary MRI results was $35.1 \%$ (26/74): space-occupying lesion in 8 patients $(10.8 \%)$ and small PG in 18 patients (24.3\%). The clinical and imaging features of patients with space-occupying lesions are summarized in Table 2. Among the 8 patients with spaceoccupying lesions, only one case reported a clinically significant headache. Furthermore, no description regarding visual blurring or loss was found in the medical records for any of the eight patients who had space-occupying lesions.

The frequency of space-occupying lesions was higher in patients with interrupted puberty $(25.0 \%, 3 / 12)$ compared to that in patients with no puberty $(4.8 \%, 1 / 21)$ or normal puberty $(9.8 \%, 4 / 41)$, but this was not statistically significant

Table 1. Demographics and hormonal characteristics in 74 women with hypogonadotropic hypogonadism who underwent pituitary magnetic resonance imaging

\begin{tabular}{|c|c|c|c|c|c|c|c|c|c|}
\hline \multirow[b]{2}{*}{ Variables } & \multirow[b]{2}{*}{ Total } & \multirow[b]{2}{*}{ No. } & \multicolumn{6}{|c|}{ Type of puberty } & \multirow[b]{2}{*}{$P$-value } \\
\hline & & & No puberty ${ }^{a)}$ & No. & $\begin{array}{l}\text { Interrupted } \\
\text { puberty }^{\text {b) }}\end{array}$ & No. & $\begin{array}{l}\text { Normal } \\
\text { pubertyc) }\end{array}$ & No. & \\
\hline Age (yr) & $23.9 \pm 6.1$ & 74 & $22.8 \pm 5.1$ & 21 & $20.5 \pm 7.0$ & 12 & $25.5 \pm 5.9$ & 41 & $0.025^{d)}$ \\
\hline Height (cm) & $161.5 \pm 6.5$ & 73 & $163.7 \pm 8.3$ & 21 & $162.1 \pm 8.3$ & 12 & $160.1 \pm 4.4$ & 40 & 0.121 \\
\hline Weight (kg) & $55.2 \pm 9.5$ & 73 & $59.0 \pm 12.3$ & 21 & $57.6 \pm 9.0$ & 12 & $52.4 \pm 7.0$ & 40 & 0.020 \\
\hline $\mathrm{BMI}\left(\mathrm{kg} / \mathrm{m}^{2}\right)$ & $21.1 \pm 3.3$ & 73 & $21.9 \pm 3.6$ & 21 & $22.1 \pm 4.6$ & 12 & $20.4 \pm 2.5$ & 40 & 0.131 \\
\hline $\mathrm{TSH}(\mu \mathrm{lU} / \mathrm{mL})$ & $2.2 \pm 1.2$ & 74 & $2.2 \pm 1.3$ & 21 & $2.8 \pm 1.5$ & 12 & $2.0 \pm 1.1$ & 41 & 0.125 \\
\hline Prolactin (ng/mL) & $8.7 \pm 6.5$ & 74 & $7.9 \pm 5.2$ & 21 & $8.0 \pm 4.8$ & 12 & $9.3 \pm 7.5$ & 41 & 0.664 \\
\hline $\mathrm{LH}(\mathrm{mlU} / \mathrm{mL})$ & $3.0 \pm 4.1$ & 74 & $0.5 \pm 1.1$ & 21 & $1.8 \pm 1.9$ & 12 & $4.5 \pm 4.7$ & 41 & $<0.0001^{\mathrm{e})}$ \\
\hline $\mathrm{FSH}(\mathrm{mlU} / \mathrm{mL})$ & $4.1 \pm 3.1$ & 74 & $1.4 \pm 1.9$ & 21 & $3.1 \pm 2.4$ & 12 & $5.8 \pm 2.6$ & 41 & $\left.<0.0001^{\mathrm{f}}\right)$ \\
\hline Estradiol (pg/mL) & $21.3 \pm 15.5$ & 48 & $13.3 \pm 11.3$ & 15 & $14.1 \pm 11.4$ & 8 & $28.4 \pm 15.7$ & 25 & $0.003^{\mathrm{g})}$ \\
\hline
\end{tabular}

Data are shown as mean \pm standard deviation or number (\%).

BMI, body mass index; LH, luteinizing hormone; FSH, follicle-stimulating hormone; TSH, thyroid-stimulating hormone.

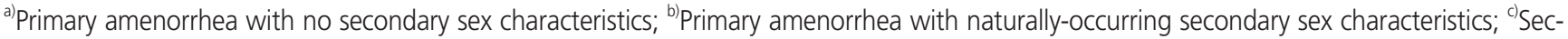
ondary amenorrhea with normal secondary sex characteristics; $\left.{ }^{d)} b<c ;{ }^{e)} a<c ;{ }^{f)} a, b<c ;{ }^{g}\right) a, b<c$. 


\title{
Obstetrics \& Gynecology Science
}

\author{
Vol. 62, No. 4, 2019
}

( $P>0.05$ ) (data not shown). The frequency of small PGs was lower in patients with normal puberty $(14.6 \%, 6 / 41)$ compared to that in patients with no puberty $(38.1 \%, 8 / 21)$ or interrupted puberty $(33.3 \%, 4 / 12)$, but this was also not statistically significant ( $P>0.05)$ (data not shown).

\section{Comparison of clinical parameters based on pituitary magnetic resonance imaging diagnoses}

A comparison of the clinical and laboratory characteristics among the three categories of pituitary MRI diagnoses is shown in Table 3. The mean levels of serum LH $(P=0.292)$ and estradiol $(P=0.187)$ were not different between patients with and without pituitary MR abnormalities. The comparison of mean FSH among the three groups was statistically different $(P=0.044)$; however, no difference was found in the post-hoc test. The mean level of serum prolactin was higher in patients with space-occupying lesions $(15.5 \mathrm{ng} / \mathrm{mL})$ than in patients with small PGs $(5.7 \mathrm{ng} / \mathrm{mL})$ or normal MRI results

Table 2. Patient characteristics of those with space-occupying lesion on pituitary magnetic resonance imaging

\begin{tabular}{|c|c|c|c|c|c|c|c|}
\hline No. & $\begin{array}{c}\text { Age at } \\
\text { diagnosis (yr) }\end{array}$ & Type of puberty & Diagnosis & $\begin{array}{l}\text { Tumor size (largest } \\
\text { diameter, } \mathrm{mm} \text { ) }\end{array}$ & $\begin{array}{c}\text { LH } \\
(\mathrm{mlU} / \mathrm{mL})\end{array}$ & $\begin{array}{c}\text { FSH } \\
(\mathrm{mlU} / \mathrm{mL})\end{array}$ & $\begin{array}{c}\text { Prolactin } \\
(\mathrm{ng} / \mathrm{mL})\end{array}$ \\
\hline 1 & 18 & Interrupted puberty & Langerhans cell histiocytosis & 13 & $<0.07$ & 0.31 & 17.64 \\
\hline 2 & 28 & No puberty & Rathke's cleft cyst ${ }^{\text {a) }}$ & 15 & 2.44 & 4.04 & 10.43 \\
\hline 3 & 20 & Interrupted puberty & Astrocytoma grade $1^{\mathrm{a})}$ & 40 & $<0.07$ & 1.84 & 10.28 \\
\hline 4 & 34 & Normal puberty & Hemangioblastoma grade $1^{\text {a) }}$ & 24 & 0.97 & 3.28 & 9.31 \\
\hline 5 & 21 & Normal puberty & Rathke's cleft cyst ${ }^{\mathrm{a})}$ & 29 & 2.99 & 3.63 & 10.27 \\
\hline 6 & 33 & Normal puberty & Pituitary tumor & 35 & 2.12 & 4.82 & 22.24 \\
\hline 7 & 20 & Normal puberty & Total hemorrhagic mass ${ }^{\mathrm{a})}$ & 16 & 4.7 & 5.4 & 35.96 \\
\hline 8 & 16 & Interrupted puberty & (raniopharyngiomaa) & 40 & 0.56 & 1.61 & 7.55 \\
\hline
\end{tabular}

$\mathrm{LH}$, luteinizing hormone; FSH, follicle-stimulating hormone.

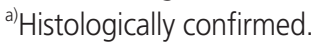

Table 3. Comparison of clinical and laboratory characteristics in 74 patients based on pituitary magnetic resonance imaging (MRI) diagnoses

\begin{tabular}{|c|c|c|c|c|c|c|c|c|c|}
\hline \multirow[b]{2}{*}{ Variables } & \multirow[b]{2}{*}{ Total } & \multirow[b]{2}{*}{ No. } & \multicolumn{6}{|c|}{ Diagnoses of pituitary MRI } & \multirow[b]{2}{*}{$P$-value } \\
\hline & & & Normal $^{a)}$ & No. & $\begin{array}{l}\text { Space-occupying } \\
\text { lesion }^{\text {b) }}\end{array}$ & No. & Small PGc) & No. & \\
\hline Age (yr) & $23.9 \pm 6.1$ & 74 & $24.0 \pm 6.1$ & 48 & $23.8 \pm 6.9$ & 8 & $23.7 \pm 6.0$ & 18 & 0.979 \\
\hline Height $(\mathrm{cm})$ & $161.5 \pm 6.5$ & 73 & $160.9 \pm 5.6$ & 47 & $157.5 \pm 6.3$ & 8 & $164.6 \pm 7.7$ & 18 & 0.022 \\
\hline Weight (kg) & $55.2 \pm 9.5$ & 73 & $52.6 \pm 8.3$ & 47 & $58.6 \pm 8.8$ & 8 & $60.5 \pm 10.5$ & 18 & 0.005 \\
\hline $\mathrm{BMI}\left(\mathrm{kg} / \mathrm{m}^{2}\right)$ & $21.1 \pm 3.3$ & 73 & $20.2 \pm 2.7$ & 47 & $23.8 \pm 4.7$ & 8 & $22.3 \pm 3.3$ & 18 & $0.003^{d)}$ \\
\hline Pituitary height (mm) & & & $6.0 \pm 1.1$ & 48 & & & $3.1 \pm 0.9$ & 18 & $<0.0001$ \\
\hline $\mathrm{TSH}(\mu \mathrm{IU} / \mathrm{mL})$ & $2.2 \pm 1.2$ & 74 & $2.1 \pm 1.2$ & 48 & $2.9 \pm 1.3$ & 8 & $2.2 \pm 1.3$ & 18 & 0.253 \\
\hline Prolactin (ng/mL) & $8.7 \pm 6.5$ & 74 & $8.7 \pm 6.3$ & 48 & $15.5 \pm 9.6$ & 8 & $5.7 \pm 1.5$ & 18 & $0.001^{\mathrm{e}}$ \\
\hline $\mathrm{LH}(\mathrm{mlU} / \mathrm{mL})$ & $3.0 \pm 4.1$ & 74 & $3.5 \pm 4.7$ & 48 & $1.7 \pm 1.6$ & 8 & $2.0 \pm 2.7$ & 18 & 0.292 \\
\hline $\mathrm{FSH}(\mathrm{mlU} / \mathrm{mL})$ & $4.2 \pm 3.1$ & 74 & $4.8 \pm 3.1$ & 48 & $3.1 \pm 1.7$ & 8 & $2.9 \pm 3.0$ & 18 & 0.044 \\
\hline Estradiol (pg/mL) & $21.3 \pm 15.5$ & 48 & $24.4 \pm 15.6$ & 30 & $14.7 \pm 11.2$ & 5 & $16.6 \pm 15.4$ & 13 & 0.187 \\
\hline
\end{tabular}

Data are shown as mean \pm SD.

BMI, body mass index; LH, luteinizing hormone; FSH, follicle-stimulating hormone; TSH, thyroid-stimulating hormone; PG, pituitary gland; SD, standard deviation.

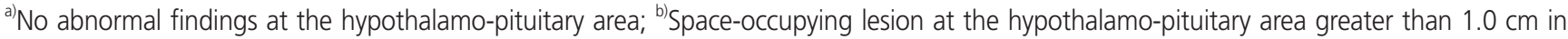
diameter; ' Vertical height of PG $<2$ SDs of the age mean; ${ }^{d)} a \leq c \leq b ;{ }^{e)} c, a<b$. 


\section{Obstetrics \& Gynecology Science}

Ji-Yeon Kang, et al. Pituitary MRI in female hypogonadism

(8.7 $\mathrm{ng} / \mathrm{mL})(P=0.001)$. The mean $\mathrm{BMI}$ was lower in patients with normal pituitary MRI results $\left(20.2 \mathrm{~kg} / \mathrm{m}^{2}\right)$ than in patients with space-occupying lesions $\left(23.8 \mathrm{~kg} / \mathrm{m}^{2}\right)$ or small PGs $\left(22.3 \mathrm{~kg} / \mathrm{m}^{2}\right)(P=0.003)$.

Comparative analyses of the clinical and hormonal parameters as well as pubertal milestones in the normal pituitary MRI and space-occupying lesion groups are shown in Table 4. Space-occupying lesions were not associated with underweight, overweight, low serum gonadotropin levels, type of amenorrhea, presence of secondary sex characteristics, or type of puberty (all $P>0.05$ ). Furthermore, small PGs were associated with low $\mathrm{LH}(<0.5 \mathrm{mlU} / \mathrm{mL}$, as stated by the reference range) ( 61.1 vs. $29.2 \%, P=0.024)$, low FSH $(<1.5 \mathrm{mlU} / \mathrm{mL}$, as stated by the reference range) ( 55.6 vs. $20.8 \%, P=0.014)$, low LH and FSH (50.0 vs. 20.8\%, $P=0.032$ ), and primary amenorrhea (66.7 vs. $35.4 \%, P=0.029$ ) when compared to the normal pituitary MRI group (Table 5). The frequencies of normal LH and FSH were significantly lower in patients with small PGs compared to that in patients with normal pituitary
MRI results $(P=0.01)$. No differences were observed for underweight, overweight, and the presence of secondary sex characteristics between the normal pituitary MRI group and the small PG group ( $P>0.05$ ).

\section{Discussion}

In this study, space-occupying lesions greater than $1 \mathrm{~cm}$ in diameter at the H-P area were present in $10.8 \%$ of female patients with $\mathrm{HH}$ who underwent pituitary MRI scans. In addition, we found no differences in the frequency of low gonadotropin levels, type of amenorrhea, or presence of secondary sex characteristics when comparing patients with space-occupying lesions and those with normal pituitary MRI results. To date, several studies have reported the diagnostic usefulness of pituitary MRI in patients with $\mathrm{HH}$; however, all of these studies were performed in male patients with hypogonadism [13-16]. To the best of our knowledge, this

Table 4. Comparative analyses of body weight, hormonal features, and pubertal milestone in the normal pituitary magnetic resonance imaging (MRI) group and the space-occupying lesion group

\begin{tabular}{|c|c|c|c|c|c|}
\hline \multirow{2}{*}{ Variables } & \multicolumn{2}{|c|}{ Normal pituitary MRI $(n=48)$} & \multicolumn{2}{|c|}{ Space-occupying lesion $(n=8)$} & \multirow{2}{*}{$P$-value } \\
\hline & Total & No. (\%) & Total & No. (\%) & \\
\hline Underweight $(\mathrm{BMI}<18.5)$ & 47 & $12(25.5)$ & 8 & $1(12.5)$ & 0.664 \\
\hline Overweight (BMI $\geq 25.0)$ & 47 & $4(8.5)$ & 8 & $2(25.0)$ & 0.206 \\
\hline Low LH (<0.5 mlU/mL) & 48 & $14(29.2)$ & 8 & $2(25.0)$ & 1 \\
\hline Low FSH (<1.5 mlU/mL) & 48 & $10(20.8)$ & 8 & $1(12.5)$ & 1 \\
\hline Low LH/low FSH & 48 & $10(20.8)$ & 8 & $1(12.5)$ & 1 \\
\hline Low LH/normal FSH & 48 & $4(8.3)$ & 8 & $1(12.5)$ & 0.552 \\
\hline Normal LH/low FSH & 48 & $0(0)$ & 8 & $0(0)$ & NA \\
\hline Normal LH/normal FSH & 48 & $34(70.8)$ & 8 & $6(75.0)$ & 1 \\
\hline \multicolumn{6}{|l|}{ Amenorrhea } \\
\hline Primary & 48 & $17(35.4)$ & 8 & $4(50.0)$ & 0.456 \\
\hline Secondary & & $31(64.6)$ & & $4(50.0)$ & \\
\hline \multicolumn{6}{|l|}{ Secondary sex characteristics } \\
\hline Absence & 48 & $12(25.0)$ & 8 & $1(12.5)$ & 0.665 \\
\hline Presence & & $36(75.0)$ & & $7(87.5)$ & \\
\hline \multicolumn{6}{|l|}{ Puberty } \\
\hline No puberty & 48 & $12(25.0)$ & 8 & $1(12.5)$ & 0.121 \\
\hline Interrupted puberty & & $5(10.4)$ & & $3(37.5)$ & \\
\hline Normal puberty & & $31(64.6)$ & & $4(50.0)$ & \\
\hline
\end{tabular}

Data are shown as number (\%).

$\mathrm{BMI}$, body mass index; LH, luteinizing hormone; FSH, follicle-stimulating hormone; NA, not available. 


\section{Obstetrics \& Gynecology Science}

Vol. 62, No. 4, 2019

Table 5. Comparative analyses of body weight, hormonal features, and pubertal milestone in the normal pituitary magnetic resonance imaging (MRI) group and the small pituitary gland (PG) group

\begin{tabular}{|c|c|c|c|c|c|}
\hline \multirow{2}{*}{ Variables } & \multicolumn{2}{|c|}{ Normal pituitary MRI $(n=48)$} & \multicolumn{2}{|c|}{ Small PG $(n=18)$} & \multirow{2}{*}{$P$-value } \\
\hline & Total & No. (\%) & Total & No. (\%) & \\
\hline Underweight $(\mathrm{BMI}<18.5)$ & 47 & $12(25.5)$ & 18 & $1(5.6)$ & 0.091 \\
\hline Overweight (BMI $\geq 25.0$ ) & 47 & $4(8.5)$ & 18 & $1(5.6)$ & 1 \\
\hline Low LH (<0.5 mlU/mL) & 48 & $14(29.2)$ & 18 & $11(61.1)$ & 0.024 \\
\hline Low FSH (<1.5 mlU/mL) & 48 & $10(20.8)$ & 18 & $10(55.6)$ & 0.014 \\
\hline Low LH/low FSH & 48 & $10(20.8)$ & 18 & $9(50.0)$ & 0.032 \\
\hline Low LH/normal FSH & 48 & $4(8.3)$ & 18 & $2(11.1)$ & 0.661 \\
\hline Normal LH/low FSH & 48 & $0(0)$ & 18 & $1(5.6)$ & 0.273 \\
\hline Normal LH/normal FSH & 48 & $34(70.8)$ & 18 & $6(33.3)$ & 0.01 \\
\hline \multicolumn{6}{|l|}{ Amenorrhea } \\
\hline Primary & 48 & $17(35.4)$ & 18 & $12(66.7)$ & 0.029 \\
\hline Secondary & & $31(64.6)$ & & $6(33.3)$ & \\
\hline \multicolumn{6}{|l|}{ Secondary sex characteristics } \\
\hline Absence & 48 & $12(25.0)$ & 18 & $8(44.4)$ & 0.144 \\
\hline Presence & & $365(75.0)$ & & $10(55.6)$ & \\
\hline \multicolumn{6}{|l|}{ Puberty } \\
\hline No puberty & 48 & $12(25.0)$ & 18 & $8(44.4)$ & 0.072 \\
\hline Interrupted puberty & & $5(10.4)$ & & $4(22.2)$ & \\
\hline Normal puberty & & $31(64.6)$ & & $6(33.3)$ & \\
\hline
\end{tabular}

Data are shown as number (\%).

$\mathrm{BMI}$, body mass index; LH, luteinizing hormone; FSH, follicle-stimulating hormone.

was the first study to present the frequency of pituitary MRI abnormalities and associated factors in female patients with $\mathrm{HH}$.

Space-occupying lesions at the H-P area is a serious but rare cause of $\mathrm{HH}$. Early diagnosis of large space-occupying lesions in the H-P area is important, because some of the lesions can lead to neurologic sequelae such as bitemporal hemianopia or unilateral optic atrophy due to the compression of the optic chiasm or optic nerve tracts. Reassuringly, however, studies performed in male patients with $\mathrm{HH}$ showed a low frequency of clinically significant macroadenoma in the H-P area (0-2.4\%) [13-16]. In 1996, a prospective study of 164 male patients with $\mathrm{HH}$ demonstrated the prevalence of total $\mathrm{H}-\mathrm{P}$ imaging abnormalities and pituitary macroadenoma to be $6.7 \%(11 / 164)$ and $2.4 \%(4 / 164)$, respectively [13]. Recently, a large retrospective case series of 281 men with $\mathrm{HH}$ who underwent pituitary MRIs demonstrated that the prevalence of pituitary microadenoma, macroadenoma, and craniopharyngioma were $8.5 \%, 1.8 \%$, and $0.4 \%$, respectively [16].
It was arbitrary to simply compare the results of studies on men with the present results; however, the frequency of large space-occupying lesions in the H-P area in our study (10.7\%) was meaningfully higher than expected. Considering the small number of patients and retrospective approach, it was uncertain whether the frequency identified in our study was representative of the actual prevalence of organic $\mathrm{H}-\mathrm{P}$ disease in female patients with $\mathrm{HH}$. Since our study analyzed only patients who underwent expensive pituitary MRIs during the diagnosis of $\mathrm{HH}$, it has been suggested that the patients with $\mathrm{HH}$ included in this study were more likely to have severe clinical symptoms and a longer duration of disease compared to that in patients with $\mathrm{HH}$ not included in the study. In fact, the duration of symptoms in 41 patients with secondary amenorrhea in our study was considerably long, with a mean duration of 39.3 months (range, 5-156 months). Such a long duration of amenorrhea might exclude patients with reversible $\mathrm{HH}$ such as functional $\mathrm{HA}$, and thereafter increase the frequency of organic brain lesions. Therefore, a large-scale, 


\section{Obstetrics \& Gynecology Science}

Ji-Yeon Kang, et al. Pituitary MRI in female hypogonadism

well-organized prospective study is needed to determine the actual prevalence of significant organic brain lesions in female patients with $\mathrm{HH}$.

There is limited information concerning the clinical and/or biochemical factors associated with pituitary MRI abnormalities in patients with $\mathrm{HH}$. A prospective study in 164 male patients with clinical hypogonadism reported that the risk of H-P imaging abnormalities increased markedly when the serum testosterone level was markedly decreased [13]. Based on this prior study, Endocrine Society guidelines recommend pituitary imaging be used for men with significant hypogonadism (total testosterone concentrations less than $150 \mathrm{ng} / \mathrm{dL}$ ) or with concerning neurologic symptoms such as headache or visual disturbance [12]. However, a subsequent large retrospective case series of 281 male patients reported no difference in testosterone or gonadotropin levels between patients with pituitary MRI abnormalities and those with normal results [16].

Because the frequency and related factors of pituitary MRI abnormalities have not yet been defined in female patients with $\mathrm{HH}$, guidelines for pituitary imaging have also not yet been established for female patients. The present study analyzed the developmental state of puberty, menstrual state, and hormonal abnormalities between patients with pituitary MR abnormalities and patients with normal MRI results. Therefore, we found no differences in gonadotropin levels, type of amenorrhea, or presence of secondary sex characteristics between patients with space-occupying lesions and those with normal pituitary MRI results. However, the frequency of space-occupying lesions was higher in patients with interrupted puberty (25.0\%) compared to that in patients with did not go through puberty $(4.8 \%)$ or patients with normal puberty $(9.8 \%)$, although this was not statistically significant.

There is little known clinical significance or diagnostic criteria for small PGs in patients with $\mathrm{HH}$. A case series of 51 men with hypogonadism reported a $17.6 \%$ prevalence of small PGs; however, the report did not present the criteria for small PGs used in the study [14]. With regards to the vertical height of a normal PG, a retrospective study performed in 60 healthy subjects (ages ranging from 8 days to 21 years) reported a pituitary vertical height reference value of 3-7 mm [18]. However, a large-scale case series of 1,020 subjects (age from 10 to 78 years) found age-related changes in the vertical height of the PG [17]. In that study, the pituitary ver- tical height peaked in the 20-to-29-year-old age group, and tended to decline with age. Because there has been no consensus regarding the criteria for small PGs, we used $<2$ SDs of the age mean for our analysis [17]. With this criteria, we found small PGs in 18 of 74 female patients with $\mathrm{HH}$, which was similar to a previous study [14].

The clinical implications of small PGs are still largely unknown; however, several studies have suggested that changes in hormone secretion are reflected in the size of the PG $[17,19]$. Furthermore, small PGs in our study were associated with low gonadotropin levels and primary amenorrhea when compared to that in the normal pituitary MRI group (Table 5). Regardless, no assumptions of causal inference can be drawn from this study. Furthermore, congenital $\mathrm{HH}$, which is a rare genetic condition characterized by inappropriately low gonadotropins, as well as primary amenorrhea [20] and failure of secondary sexual development were found in $25 \%$ of patients in the normal-sized pituitary MRI group in our study (data not shown). Therefore, further studies are needed to determine the relationship between pituitary hormone secretion and pituitary size.

In this study, serum estradiol measurements were not uniformly performed in study subjects. The mean level of serum estradiol in patients who were tested was $21.3 \pm 15.5 \mathrm{pg} / \mathrm{mL}$ (range, 1.0-63.5 pg/mL), which was consistent with hypogonadism. However, low levels of estrogen milieu were not biochemically confirmed in the 16 patients who were not tested. Although low gonadotropin levels and clinically evident hypogonadism provide a substantial degree of diagnostic accuracy, we could not completely exclude the possibility that these limitations may have affected the accuracy of $\mathrm{HH}$ diagnoses in patients who were not tested.

In conclusion, this was the first study to report the frequency of pituitary MRI abnormalities and associated factors in female patients with $\mathrm{HH}$. In our study, no significant clinical, hormonal, or pubertal factors were found to effectively predict space-occupying lesions in patients with $\mathrm{HH}$. However, the frequency of space-occupying lesions was higher in patients with interrupted puberty compared than in no puberty or normal puberty groups. Considering the potential limitations such as the small number of study subjects as well as the retrospective approach, the prevalence of pituitary MRI abnormalities in our study should be verified by further largescale prospective studies. 


\section{Obstetrics \& Gynecology Science}

Vol. 62, No. 4, 2019

\section{Conflict of interest}

No potential conflicts of interest relevant to this article were reported.

\section{Ethical approval}

The Institutional Review Board (IRB) of the CHA Bundang Medical Center of CHA University, Gyeonggi-do, Korea, approved this study (IRB No. 2018-04-045).

\section{Patient consent}

Obtaining an informed consent from the study participants was waived based on the minimal clinical risk involved, study being done retrospectively.

\section{References}

1. Silveira LF, MacColl GS, Bouloux PM. Hypogonadotropic hypogonadism. Semin Reprod Med 2002;20:327-38.

2. Warren MP, Brooks-Gunn J, Hamilton LH, Warren LF, Hamilton WG. Scoliosis and fractures in young ballet dancers. Relation to delayed menarche and secondary amenorrhea. N Engl J Med 1986;314:1348-53.

3. Hergenroeder AC. Bone mineralization, hypothalamic amenorrhea, and sex steroid therapy in female adolescents and young adults. J Pediatr 1995;126:683-9.

4. Misra M, Golden NH, Katzman DK. State of the art systematic review of bone disease in anorexia nervosa. Int J Eat Disord 2016;49:276-92.

5. Reindollar RH, Byrd JR, McDonough PG. Delayed sexual development: a study of 252 patients. Am J Obstet Gynecol 1981;140:371-80.

6. Lee DY, Oh YK, Yoon BK, Choi D. Prevalence of hyperprolactinemia in adolescents and young women with menstruation-related problems. Am J Obstet Gynecol 2012;206:213.e1-213.e5.

7. Silveira LF, Latronico AC. Approach to the patient with hypogonadotropic hypogonadism. J Clin Endocrinol Metab 2013;98:1781-8.

8. Genazzani AD, Ricchieri F, Lanzoni C, Strucchi C, Jasonni
VM. Diagnostic and therapeutic approach to hypothalamic amenorrhea. Ann N Y Acad Sci 2006;1092:10313.

9. Hansen KA, Tho SP, Gomez F, McDonough PG. Nonfunctioning pituitary macroadenoma presenting with mild hyperprolactinemia and amenorrhea. Fertil Steril 1999;72:663-5.

10. Kokshoorn NE, Wassenaar MJ, Biermasz NR, Roelfsema F, Smit JW, Romijn JA, et al. Hypopituitarism following traumatic brain injury: prevalence is affected by the use of different dynamic tests and different normal values. Eur J Endocrinol 2010;162:11-8.

11. Nishi $Y$, Hamamoto K, Fujita N, Okada S. Empty sella/ pituitary atrophy and endocrine impairments as a consequence of radiation and chemotherapy in longterm survivors of childhood leukemia. Int J Hematol 2011;94:399-402.

12. Bhasin S, Cunningham GR, Hayes FJ, Matsumoto AM, Snyder PJ, Swerdloff RS, et al. Testosterone therapy in men with androgen deficiency syndromes: an Endocrine Society clinical practice guideline. J Clin Endocrinol Metab 2010;95:2536-59.

13. Citron JT, Ettinger $B$, Rubinoff $H$, Ettinger VM, Minkoff J, Hom F, et al. Prevalence of hypothalamic-pituitary imaging abnormalities in impotent men with secondary hypogonadism. J Urol 1996;155:529-33.

14. Rhoden EL, Estrada C, Levine L, Morgentaler A. The value of pituitary magnetic resonance imaging in men with hypogonadism. J Urol 2003;170:795-8.

15. Hirsch D, Benbassat C, Toledano Y, S'chigol I, Tsvetov G, Shraga-Slutzky I, et al. Pituitary imaging findings in male patients with hypogonadotrophic hypogonadism. Pituitary 2015;18:494-9.

16. Dalvi M, Walker BR, Strachan MW, Zammitt NN, Gibb FW. The prevalence of structural pituitary abnormalities by MRI scanning in men presenting with isolated hypogonadotrophic hypogonadism. Clin Endocrinol (Oxf) 2016;84:858-61.

17. Tsunoda A, Okuda O, Sato K. MR height of the pituitary gland as a function of age and sex: especially physiological hypertrophy in adolescence and in climacterium. AJNR Am J Neuroradiol 1997;18:551-4.

18. Argyropoulou M, Perignon F, Brunelle F, Brauner R, Rappaport R. Height of normal pituitary gland as a function of age evaluated by magnetic resonance imaging in chil- 


\section{Obstetrics \& Gynecology Science}

Ji-Yeon Kang, et al. Pituitary MRI in female hypogonadism

dren. Pediatr Radiol 1991;21:247-9.

19. Doraiswamy PM, Potts JM, Axelson DA, Husain MM, Lurie $\mathrm{SN}, \mathrm{Na} \mathrm{C}$, et al. MR assessment of pituitary gland morphology in healthy volunteers: age- and gender-related differences. AJNR Am J Neuroradiol 1992;13:1295-9.

20. Bianco SD, Kaiser UB. The genetic and molecular basis of idiopathic hypogonadotropic hypogonadism. Nat Rev Endocrinol 2009;5:569-76. 